\title{
Modelling of the traditional solar drying kinetics of cassava (Manihot esculenta Crantz) using Multilayer Perceptron: A case study
}

\author{
Yao Marcel Konan, Kabran E.E. Andrée-Marie, Trokourey Albert \\ Félix Houphouët-Boigny University of Cocody-Abidjan, UFR SSMT, Physical Chemistry laboratory, B.P. V34 Abidjan, Côte d'Ivoire
}

Correspondence Author: Yao Marcel Konan, Félix Houphouët-Boigny University of Cocody-Abidjan, UFR SSMT, Physical Chemistry laboratory, B.P. V34 Abidjan, Côte d'Ivoire.

E-mail:- yaomarcelkonan@gmail.com

Received date: 15 September 2019, Accepted date: 22 December 2019, Online date: 31 December 2019

Copyright: (C) 2019 Yao Marcel Konan et al, This is an open-access article distributed under the terms of the Creative Commons Attribution License, which permits unrestricted use, distribution, and reproduction in any medium, provided the original author and source are credited.

\begin{abstract}
Studies relating to the modelling of the traditional solar drying kinetics of cassava (Manihot esculenta Crantz) by artificial neural networks, particularly by the multilayer perceptron, are very little provided in the scientific literature. So, it is important to lead studies on this subject to contribute to thorough knowledge of this drying process of cassava. It is in this context this study was carried out, with its main objective the static and hourly dynamics modelling of the moisture contents of six cassava varieties intensively grown in Côte d'Ivoire by using the multilayer perceptron, hence its originality. In this study, the implementation of the multilayer perceptron was done with the Levenberg-Marquardt algorithm for model optimization. The best model for the static modelling of the moisture contents for all cassava varieties considered in this study is 7- 4-1 model. This model explains to $97.61 \%\left(R 2_{\text {app }}\right)$ the variations of the seven input parameters and predicts at $95.45 \%(\mathrm{R} 2$ test) the static evolution of their moisture contents. For the hourly dynamics modelling of the moisture contents for all cassava varieties considered in this study, it is best translated by 8-2-1 model. This model explains to $98.01 \%\left(R 2_{\text {app}}\right.$ ) the hourly variations of the 8 input parameters and predicts at $96.24 \%$ ( $R 2_{\text {test }}$ ) the hourly dynamics of theirs moisture contents. These two models obtained present a good approach to the modeling of the traditional solar drying kinetics of cassava. So, this study has once again shown the great capacity of artificial neural networks in general, and in particular of the multilayer perceptron, for the modelling of any complex phenomenon, such as the traditional solar drying kinetics of plants.
\end{abstract}

Keywords: Artificial Neural Networks, Cassava modeling, Côte d'Ivoire, Multilayer perceptron, Traditional solar drying

\section{INTRODUCTION}

Studies relating to the thermal drying of plants, particularly those concerning solar drying have been always important since the works of Lewis (1921) and Sherwood (1929). One of the characteristics of these studies is the modeling of their drying kinetics. For this purpose, several models have always been developed. Most of these models are semi-empirical or empirical models based on numerical simulations (Al-Ali et al., 2019; Castro et al., 2018; Djebli et al., 2020) and knowledge models (Badoui et al., 2019; Ouabou et al., 2018; Wang et al., 2019). The implementation of these models is tedious and expensive, with limited applications. As a result, they have no generalization power. To overcome these disadvantages for such studies, many "black box" type models are increasingly used in this context. One of the most used models for that is Artificial Neural Networks (ANNs), particularly MultiLayer Perceptron (MLP). The parsimony and speed of MLP have doing it a true statistical tool capable of any complex phenomenon modeling (Yao et al., 2016a; 2016b). Thus, it is used in any scientific field. The prowess of this model in solar drying processes is abundantly provided in the scientific literature, especially for that of plants (Akmel, 2010, Kaveh et al., 2018, Karidioula et al., 2018; Onwude et al., 2019). However, its application in the modeling of cassava thermal drying kinetic, particularly those of the traditional solar drying, is very little study. This fact is, therefore, a real interest of study.

Scientifically known as Manihot esculenta or Manihot esculenta Crantz, cassava is one of three major sources of polysaccharides, with yams and breadfruits in tropical countries (Abass et al., 2014, Diallo et al., 2013). In 2017, its global production was estimated by FAOSTAT (2017) at 291,992,645 tones, of which $55.2 \%$ from sub-Saharan Africa. It is one of the 
most widely consumed agricultural products in the Southern Hemisphere, especially from meals concocted from its flour, obtained mostly by the traditional solar drying of its flesh in this geographical area (Del Villa et al., 2017, Diaz et al., 2018, RivadeneyraDominguez et al., 2013, Yahya et al., 2019). Thus, studies related to cassava solar drying are still of real scientific interest. This fact is illustrated by recent works, as shown by those of Aviara et al. (2014), Yahaya et al. (2016) and Tieu et al. (2019). However, models used in these studies, in general, are knowledge models and/or empirical or semi-empirical models. Also, these studies refer to a single cassava variety generally undefined, on the one hand, and don't provide any information on the modeling of the cassava traditional solar drying kinetics, which is the most solar drying process used in tropical countries, on the other hand. Therefore, it is useful to conduct this study which aims to model the traditional solar drying kinetics of six cassava varieties grown intensely in Côte d'Ivoire by ANN's, particularly by MLP. The main objective of this study is the static and hourly dynamics modelling of the moisture contents of these cassava varieties during their traditional solar drying by using MLP.

\section{MATERIAL AND METHODS}

\subsection{Scenarios implementation}

The static modelling and the dynamic modelling of the traditional solar drying kinetics of six cassava varieties grown in Côte d'Ivoire were conducted during this study. These six cassava varieties are known in Côte d'Ivoire under the name of Akaman, Bocou, Bonoua, Manioc blanc, Yacé and Yavo. These modelling have consisted in the prediction of the moisture contents evolution of all these cassava varieties during this drying process.

For the static modelling of the moisture contents of these cassava varieties, their moisture contents has been the single output of MLP (TE). Seven parameters were used as input parameters of this model:

- the mass of cassava samples ( $\mathrm{m})$, expressed in $\mathrm{kg}$;

- the different exchange surfaces (SC) of cassava samples, expressed in $\mathrm{m}^{2}$;

- the density of cassava samples $(\varphi)$, expressed in $\mathrm{g} / \mathrm{cm}^{3}$ or $\mathrm{kg} / \mathrm{m}^{3}$;

- the mean daily ambient air temperature $(\mathrm{Tj})$ corresponding to the date $\mathrm{t}$ (cumulative drying time), obtained from the meteorological forecasts in the study area, expressed in ${ }^{\circ} \mathrm{C}$;

- the mean daily ambient air humidity (HA) corresponding to the date $\mathrm{t}$ (cumulative drying time), obtained from the weather forecasts in the study area, expressed in \%;

- the mean daily ambient airspeed (Vja) corresponding to the date $\mathrm{t}$ (cumulative drying time), obtained from the meteorological forecasts in the study area, expressed in $\mathrm{m} / \mathrm{s}$;

- the monthly global radiation (RGM) in the study area corresponding to the study period, expressed in $\mathrm{KWh} / \mathrm{m}^{2} / \mathrm{day}$.

In the case of the hourly dynamic modelling of the moisture contents of these cassava varieties, the parameter "cumulative drying time (HSC) (expressed in hours)" was added to the seven input parameters used for the static modelling of their moisture contents. In this study, it was used 6160 data set for static modelling and 6930 data set for the hourly dynamic modelling of their moisture contents. These data were provided by the study doing by Kabran et al. (2019) on the traditional solar drying kinetics of these six Cassava varieties.

The daily forecast data of temperature, wind speed, and air humidity over the study period were provided by AccuWeather (2019). As for the data relating to global monthly radiation, they were by SODEXAM (2016), and this over the period from 1988 to 2016.

\subsection{MLP implementation in this study}

The MLP implementation was done using the Levenberg (1944)-Marquardt (1963) algorithm for optimizing the weakness of prediction errors during the learning phase. The adaptive simulation rate method was used to accelerate this phase. The learning rate was initially set at 0.2 and gradually reduced to 0.01 with 0.5 sequences. The different parameters were normalized from the formula (1) and coded in a range between 0 and $n$ ( $n$ belonging to the natural numbers). The weights of the network were initialized before their modification during the learning phase.

$$
x_{n i}=\frac{2\left(x_{i}-x_{\min }\right)}{\left(x_{\max }-x_{\min }\right)}-1
$$

with: $\mathrm{x}_{\mathrm{ni}}$, the normalized data between -1 and $+1 ; \mathrm{x}_{\mathrm{i}}$, the real value of the data $\mathrm{i} ; \mathrm{X}_{\max }$, the maximum value of the dataset used and $\mathrm{x}_{\min }$, the minimum value of the dataset used.

The architecture of the network has been optimized by varying the number of hidden layers from 1 to 15 . For each value of the hidden layer, the simulations were carried out 1500 times and the best result of the corresponding network architecture was recorded. This best result corresponds to the one with the highest correlation values (R) simultaneously during the learning, validation and test phases, with very low means squared errors (MSE). Fifty percent (50\%), twenty-five percent (25\%) and twenty-five percent $(25 \%)$ of the data were used for the learning, validation and testing phases respectively. In this study, MLP implementation was done using the Neural Toolbox module of MATLAB Release 2019a (2019).

\subsection{Conditions for the choice of the best model}

In this study, the choice of the best model was done taking into account the correlation values obtained in the learning phase $\left(R_{\text {app }}\right)$ and the test phase $\left(R_{\text {test }}\right)$. The best model is that which have shown $R_{\text {app }}$ maximum value and $R_{\text {test }}$ maximum value 
simultaneously. In the case where $\mathrm{R}_{\text {app }}$ maximum value and $\mathrm{R}_{\text {test }}$ maximum value are obtained for the different models, the best model has been that has presented the highest arithmetic mean ( $R$ ) of $R_{a p p}$ and $R_{\text {test }}(4)$.

$$
\mathrm{R}=\frac{\mathrm{R}_{\mathrm{app}}+\mathrm{R}_{\mathrm{test}}}{2}
$$

\subsection{Statistical methods used for validation of the chosen models:}

For the validation of the chosen models, the validation conditions of MLP models established by Yao et al. (2016a, 2016b, 2017) have been used. Thus, a model is validated if the following conditions are observed:

$-\mathrm{R} 2_{\text {test }}>0.5\left(\mathrm{R}_{\text {test }}>0.7\right)$, ie the model must predict more than $50 \%$ the phenomenon studied during the test phase;

- the mean square errors (MSE) and the root mean square errors (RMSE) during the test phase must be relatively very low;

- the mean prediction error $\left(\mathrm{e}_{\text {moy }}\right)$ between the experimental values $\left(\mathrm{Y}_{\mathrm{obs}}\right)$ and those predicted $\left(\mathrm{Y}_{\mathrm{pr}}\right)$ by the model during the test, must be relatively very low. This error is calculated according to the following equation:

$$
\mathrm{e}_{\text {moy }}=\left|\frac{\sum_{1}^{\mathrm{N}}\left(\mathrm{Y}_{\mathrm{pr}}-\mathrm{Y}_{\mathrm{obs}}\right)}{\mathrm{N}}\right|
$$

where $\mathrm{N}$ is the number of samples in the "test" database;

- the relative mean deviation error $(\Delta(\%))$ between the experimental values (Yobs) and those predicted by the model (Ypr) during the test must be less than $10 \%$ as recommended for the statistical models (Noumi, 2004). It is obtained according to the following equation:

$$
\Delta(\%)=\left|\frac{100}{\mathrm{~N}} \times \sum_{1}^{\mathrm{N}}\left(\frac{\mathrm{Y}_{\mathrm{pr}}-\mathrm{Y}_{\mathrm{obs}}}{\mathrm{Y}_{\mathrm{obs}}}\right)\right|
$$

\section{RESULTS AND DISCUSSION}

\subsection{Results}

\subsubsection{Choice of the best models}

The results obtained in the simulations for the different scenarios are presented in Tables 1 and 2 . With reference to the established criteria for the choice of the best models, the best model for the static modelling of the moisture contents for all cassava varieties considered in this study is 7- 4-1 model. This model explains to $97.61 \%$ ( $\left.\mathrm{R} 2_{\text {app }}\right)$ the variations of the seven input parameters and predicts at $95.45 \%(\mathrm{R} 2$ test $)$ the static evolution of their moisture contents. For the hourly dynamic modelling of the moisture contents of these cassava varieties, it is best translated by the 8-2-1 model. This model explains to $98.01 \%$ (R2 app) the hourly variations of the 8 input parameters and predicts at $96.24 \%\left(\mathrm{R} 2_{\text {test }}\right)$ the hourly dynamics of their moisture contents.

Table 1: Characteristics of the different models established for the static modeling of the moisture contents for all cassava varieties considered in this study

\begin{tabular}{|c|c|c|c|c|c|}
\hline Model & $\boldsymbol{R}_{\text {app }}$ & $\boldsymbol{R}_{\text {test }}$ & $\boldsymbol{R}$ & $\boldsymbol{M S E}_{\text {App }}$ & $\boldsymbol{M S E}_{\text {test }}$ \\
\hline $7-1-1$ & 0.978 & 0.972 & 0.975 & 0.015 & 0.022 \\
\hline $7-2-1$ & 0.981 & 0.966 & 0.974 & 0.014 & 0.02 \\
\hline $7-3-1$ & 0.983 & 0.971 & 0.977 & 0.012 & 0.026 \\
\hline$* 7-4-1$ & 0.988 & 0.977 & 0.983 & 0.013 & 0.028 \\
\hline $7-5-1$ & 0.984 & 0.959 & 0.971 & 0.01 & 0.038 \\
\hline $7-6-1$ & 0.996 & 0.964 & 0.98 & 0.004 & 0.174 \\
\hline $7-7-1$ & 0.994 & 0.937 & 0.966 & 0.004 & 0.258 \\
\hline $7-8-1$ & 0.98 & 0.974 & 0.981 & 0.007 & 0.108 \\
\hline $7-9-1$ & 0.99 & 0.966 & 0.978 & 0.005 & 0.128 \\
\hline $7-10-1$ & 0.989 & 0.951 & 0.970 & 0.005 & 0.041 \\
\hline $7-11-1$ & 0.998 & 0.932 & 0.965 & 0.007 & 0.094 \\
\hline $7-12-1$ & 0.989 & 0.966 & 0.977 & 0.004 & 0.102 \\
\hline $7-13-1$ & 0.995 & 0.945 & 0.97 & 0.001 & 0.108 \\
\hline $7-14-1$ & 0.993 & 0.954 & 0.974 & 0.005 & 0.023 \\
\hline $7-15-1$ & 0.994 & 0.966 & 0.98 & 0.001 & 0.117 \\
\hline
\end{tabular}

*The best model

$\mathrm{R}_{\mathrm{app}}$, the correlation coefficient during the learning phase;

$\mathrm{R}_{\text {test }}$, the correlation coefficient during the test phase;

$\mathrm{R}$, the arithmetic mean of $\mathrm{R}_{\text {app }}$ and $\mathrm{R}_{\text {test }}$;

$\mathrm{MSE}_{\mathrm{app}}$, the mean square errors during the learning phase;

$\mathrm{MCE}_{\text {test }}$, the mean square errors during the test phase. 
44

Citation: Yao Marcel Konan et al., 2019. Modelling of the traditional solar drying kinetics of cassava (Manihot esculenta Crantz) using Multilayer Perceptron: A case study. Australian Journal of Basic and Applied Sciences, 13(12): 41-48. DOI: 10.22587/ajbas.2019.13.12.7

Table 2: Characteristics of the different models established for the hourly dynamic modeling of the moisture contents for all cassava varieties considered in this study

\begin{tabular}{|c|c|c|c|c|c|}
\hline Model & $\boldsymbol{R}_{\text {app }}(\boldsymbol{t})$ & $\boldsymbol{R}_{\text {test }}(\boldsymbol{t})$ & $\boldsymbol{R}(\boldsymbol{t})$ & $\boldsymbol{M S E}_{\text {App }}$ & $\boldsymbol{M S E}_{\text {test }}$ \\
\hline $8-1-1$ & 0.979 & 0.97 & 0.974 & 0.015 & 0.023 \\
\hline$* 8-2-1$ & 0.99 & 0.981 & 0.986 & 0.013 & 0.027 \\
\hline $8-3-1$ & 0.991 & 0.975 & 0.983 & 0.014 & 0.028 \\
\hline $8-4-1$ & 0.991 & 0.973 & 0.982 & 0.01 & 0.023 \\
\hline $8-5-1$ & 0.989 & 0.967 & 0.978 & 0.008 & 0.069 \\
\hline $8-6-1$ & 0.988 & 0.942 & 0.965 & 0.010 & 0.03 \\
\hline $8-7-1$ & 0.99 & 0.961 & 0.976 & 0.008 & 0.032 \\
\hline $8-8-1$ & 0.988 & 0.97 & 0.979 & 0.007 & 0.038 \\
\hline $8-9-1$ & 0.988 & 0.945 & 0.967 & 0.01 & 0.033 \\
\hline $8-10-1$ & 0.99 & 0.952 & 0.971 & 0.002 & 0.26 \\
\hline $8-11-1$ & 0.99 & 0.897 & 0.944 & 0.007 & 0.065 \\
\hline $8-12-1$ & 0.99 & 0.958 & 0.973 & 0.006 & 0.072 \\
\hline $8-13-1$ & 0.988 & 0.933 & 0.961 & 0.006 & 0.079 \\
\hline $8-14-1$ & 0.992 & 0.949 & 0.971 & 0.004 & 0.059 \\
\hline $8-15-1$ & 0.988 & 0.972 & 0.98 & 0.006 & 0.073 \\
\hline
\end{tabular}

*The best model

$\mathrm{R}_{\mathrm{app}}(\mathrm{t})$, the correlation coefficient during the learning phase;

$\mathrm{R}_{\text {test }}(\mathrm{t})$, the correlation coefficient during the test phase;

$\mathrm{R}$, the arithmetic mean of $\mathrm{R}_{\mathrm{app}}(\mathrm{t})$ and $\mathrm{R}_{\text {test }}(\mathrm{t})$;

$\mathrm{MSE}_{\mathrm{app}}$, the mean square errors during the learning phase;

$\mathrm{MCE}_{\text {test }}$, the mean square errors during the test phase.

\subsubsection{Validity of the chosen models}

As shown in Table 3, the two models established in this study have characteristics that verify the validation conditions established. Thus, these two models are validated. The architectures of 7-4-1 model and 8-2-1 model are given respectively in figures 1 and 2. The representations of the normalized values predicted as a function of the normalized experimental values for these models are given in figures 3 and 4 .

Table 3: Validation of 7-4-1 model and 8-2-1 model

\begin{tabular}{|c|c|c|c|c|}
\hline $\begin{array}{c}\text { Model validation } \\
\text { parameters }\end{array}$ & $\begin{array}{c}7-4-1 \\
\text { model }\end{array}$ & $\begin{array}{c}\text { Observation with respect to } \\
\text { validation criteria }\end{array}$ & $\begin{array}{l}8-2-1 \\
\text { model }\end{array}$ & $\begin{array}{c}\text { Observation with respect to } \\
\text { validation criteria }\end{array}$ \\
\hline$R 2_{\text {test }}$ & 0,954 & $>0,5$ & 0,962 & $>0,5$ \\
\hline$M C E_{\text {test }}$ & 0,028 & Very low & 0,013 & Very low \\
\hline$R M C E_{\text {test }}$ & 0,167 & Very low & 0,114 & Very low \\
\hline$e_{\text {moy }}$ & 0,410 & Very low & 0,087 & Very low \\
\hline$\Delta(\%)$ & 1,119 & $<10 \%$ & 3,931 & $<10 \%$ \\
\hline $\begin{array}{l}\text { Model state (Validated or } \\
\text { not validated) }\end{array}$ & Validated & & Validated & \\
\hline
\end{tabular}

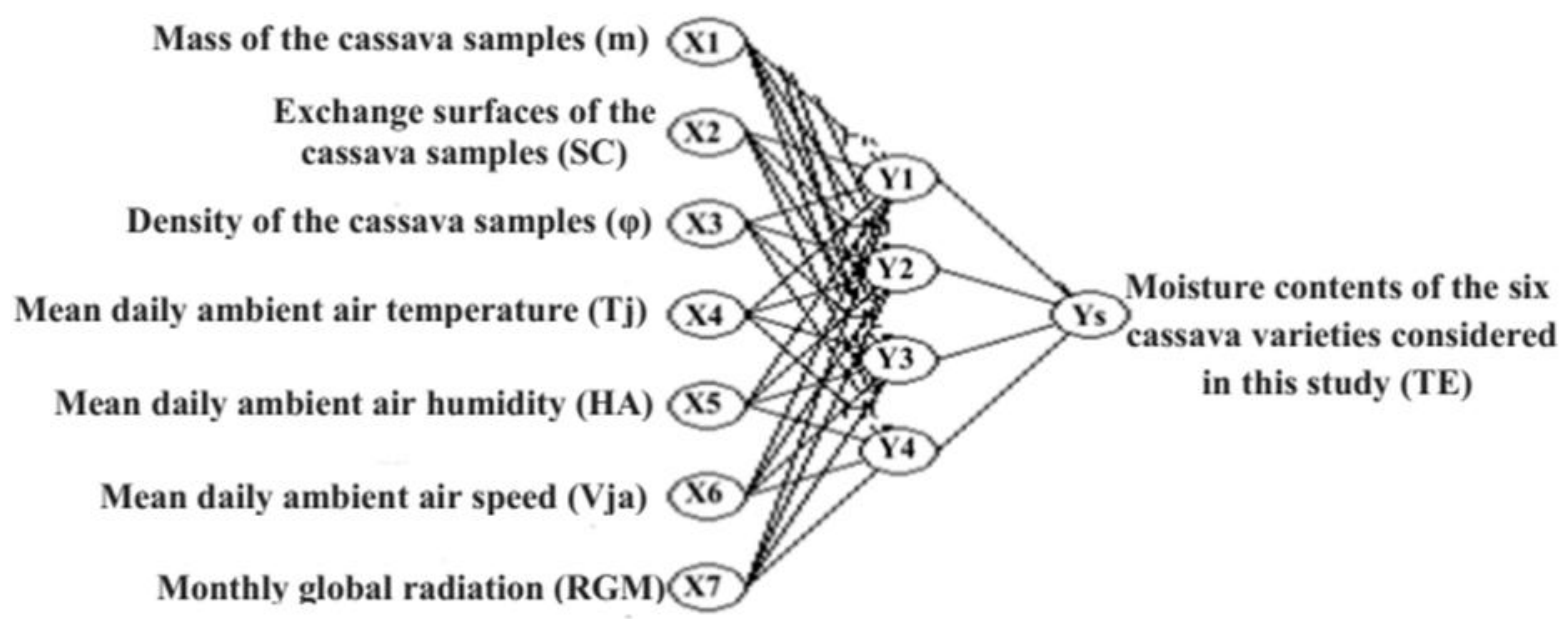

Figure 1: Architecture of 7-4-1 model. 


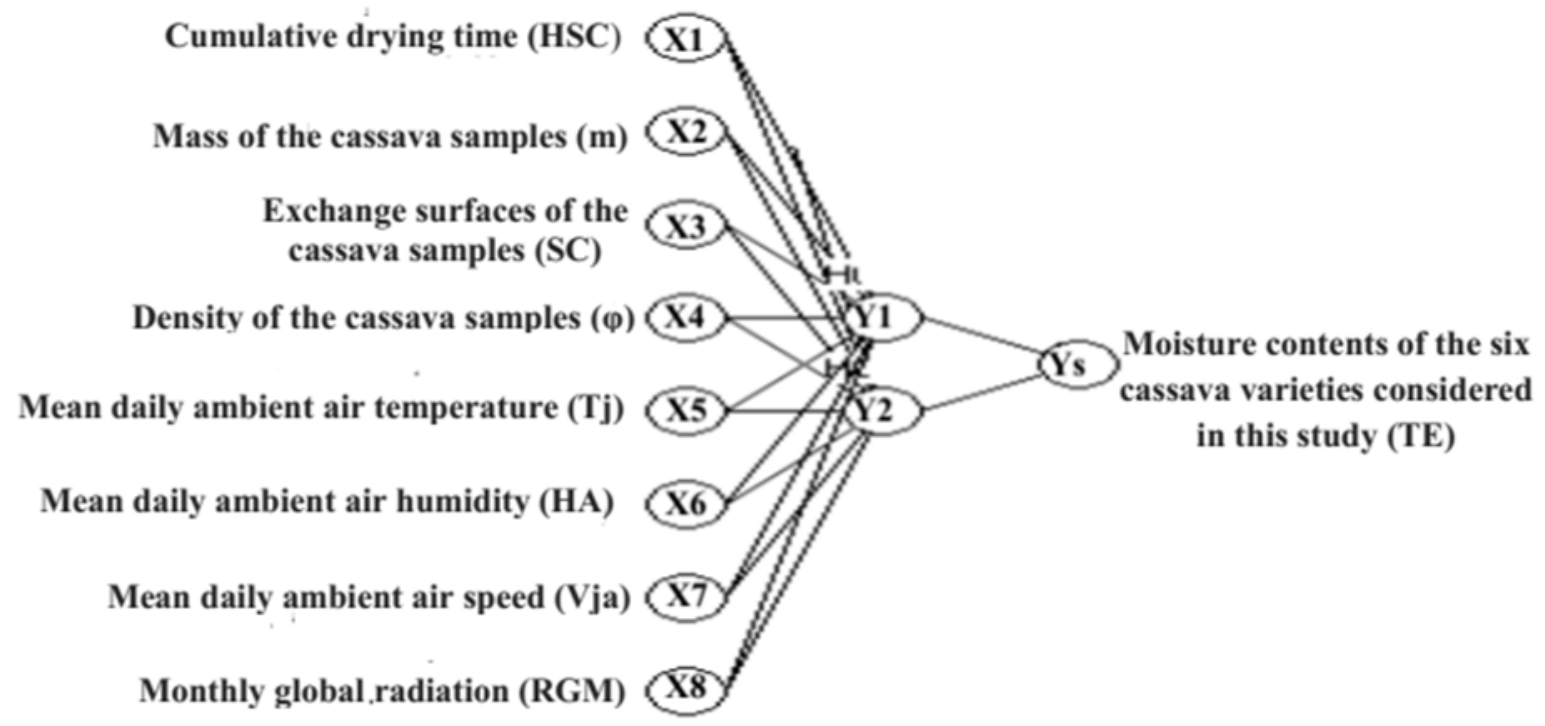

Figure 2: Architecture of 8-2-1 model.

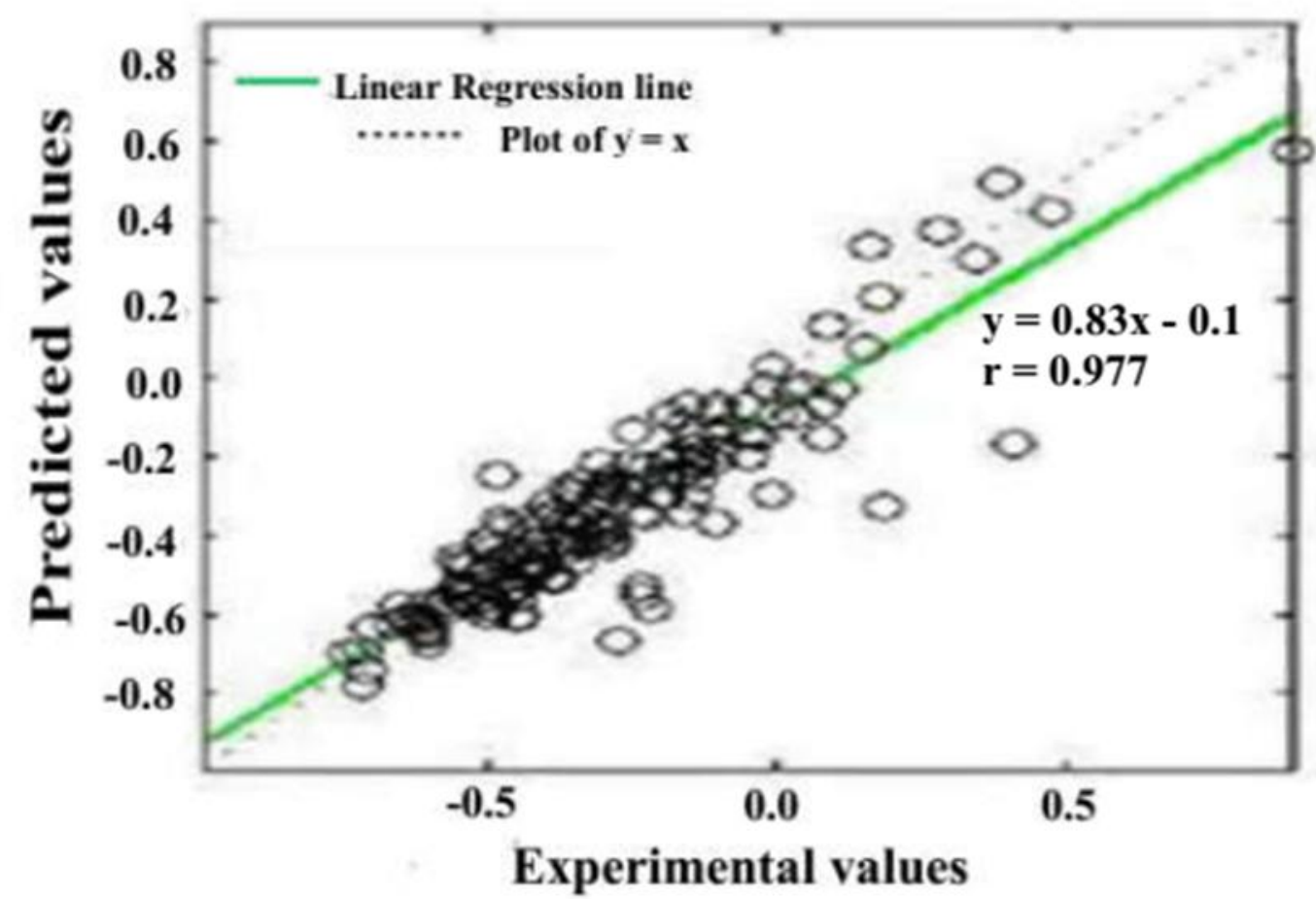

Figure 3: Representation of the predicated values as a function of the experimental values for the static modeling of moisture contents for the six cassava varieties considered in this study. 


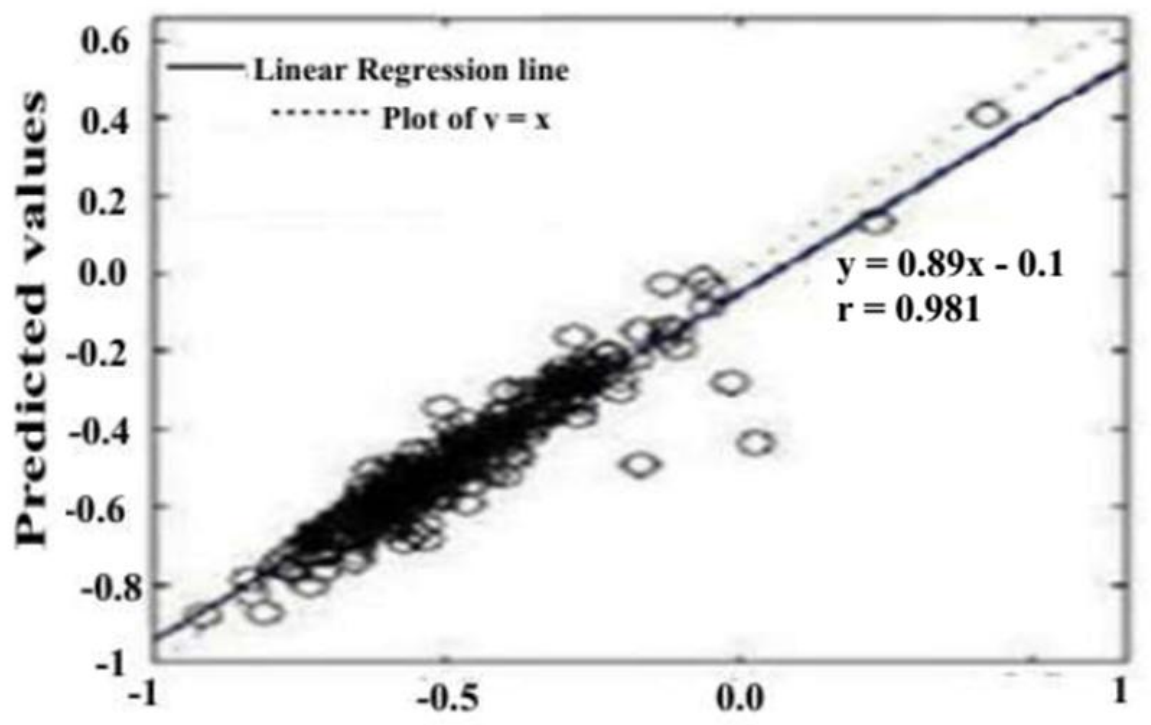

Experimental values

Figure 4: Representation of the predicated values as a function of the experimental values for the hourly dynamic modeling of moisture content for the six cassava varieties cassava considered in this study.

\subsection{Discussion}

The different results obtained in this study once again confirm the ability of MLP to model any complex phenomenon (Yao et al., 2016a, 2016b), particularly that of the traditional solar drying kinetics of plants. Indeed, the phenomena involved in this kind of solar drying are based on climatological conditions (ambient air temperature, ambient air humidity, wind speed, intensity and duration of insolation, etc.) that fluctuate a lot during this process. Also, the nature, the form and the composition of the product to be dried, as well as the drying rack strongly contribute to this fact (Kabran et al.,2019). As a result, a total or partial consideration of all these parameters in modelling of the traditional drying kinetics of plants by empirical or semi-empirical models and by knowledge models is very tedious; and the results obtained would not be satisfactory. This fact would explain the scarcity of works related to this subject in the scientific literature.

On the other hand, modelling by these models of the drying kinetics of plants in hybrid or non-hybrid solar furnaces, where the drying parameters are known and controllable, leads to very satisfactory results and is very provided in the scientific literature (César et al., 2020; Mehran et al., 2019; Seeranguraya et al., 2019; Torkashvand et al., 2017). Moreover, the great ability of MLP to model the drying kinetics of plants in hybrid or non-hybrid solar furnaces has been shown by numerous studies, including those of Kaveh et al., 2018, Karidioula et al., 2018 and Wilkins et al., 2019. So, MLP can model any solar drying phenomena, therefore ANN's in general (Benali et al., 2019, Çelik et al., 2016, Elsheikh et al. , 2019).

The performances of MLP models established in this study are very close to those of MLP models obtained by Akmel (2010) and Karidioula et al. (2018) in the case of the solar drying of cocoa beans. As was the case for these authors, the number of neurons on the hidden layer of the models established in this study is relatively low. This observation confirms the strong correlation between the input and the output parameters used in this study. Indeed, the relative ambient air humidity, the ambient air speed, the air ambient temperature, the product mass, the global solar radiation and the density of the product are very influential parameters in solar drying plants (Dadda et al., 2008, Jain and Tiwari, 2003), as shown again by these models.

\section{CONCLUSION}

This study has highlighted the good prediction of the traditional solar drying kinetics of plants by AANs in general, and by MLP in particular. Thus, it contributes to the scientific knowledge of this complex drying mode, depending on the weather conditions. It could serve as a basis for very complex drying studies.

\section{Acknowledgments}

The authors thank Professor ASSIDJO Nogbou Emmanuel of Félix Houphouët-Boigny of Yamoussokro (Côte d'Ivoire) for its great help in this study.

\section{REFERENCES}

Abass, A.B., E. Towo, I. Mukuka, R. Okechukwu, R. Ranaivoson, G. Tarawali and E. Kanju, 2014. Growing Cassava-A training manual from production to postharvest. Eds: International Institute of Tropical Agriculture (IITA), Ibadan, Nigeria.

AccuWeather, 2019. https://www.accuweather.com/fr/ci/abidjan/113725/march weather/113725. From 21 march to 29 March 2019. 
Citation: Yao Marcel Konan et al., 2019. Modelling of the traditional solar drying kinetics of cassava (Manihot esculenta Crantz) using Multilayer Perceptron: A case study. Australian Journal of Basic and Applied Sciences, 13(12): 41-48. DOI: 10.22587/ajbas.2019.13.12.7

Akmel, C., 2010. Séchage Solaire des fèves de cacao: étude expérimentale et modélisation de la cinétique de séchage, Thèse de doctorat, Université d'Abobo-Adjamé, Côte d'Ivoire.

Al-Ali, M., and R Parthasarathy, 2019. Modeling and kinetics study of novel microwave irradiation drying of naproxen sodium drug. Powder Technology, 345: 766-774. DOI: 10.1016/j.powtec.2019.01.046

Aviara, N.A., L.N. Onuoha, O.E. Falola and J.C. Igbeka, 2014. Energy and exergy analyses of native cassava starch drying in a tray dryer. Energy, 73: 809-81. DOI : $10.1016 / j$.energy.2014.06.087

Badaoui, O., S. Hanini, A. Djebli, B. Haddad and A. Benhamou, 2019. Experimental and modelling study of tomato pomace waste drying in a new solar greenhouse: Evaluation of new drying models. Renewable Energy, 133:144-155. DOI: 10.1016/i.renene.2018.10.020

Benali, L., G. Notton, A. Fouilloy, C. Voyant and R. Dizene, 2019. Solar radiation forecasting using artificial neural network and random forest methods: Application to normal beam, horizontal diffuse and global components. Renewable Energy, 132: 871-884. DOI: $10.1016 /$ j.renene.2018.08.044

Castro, A.M., E.Y. Mayorga and F.L. Moreno, 2018. Mathematical modelling of convective drying of fruits: A review. Journal of Food Engineering, 223: 152-167. DOI: 10.1016/j.jfoodeng.2017.12.012

Çelik, Ö., A. Teke and H.B. Yıldırım, 2016. The optimized artificial neural network model with Levenberg-Marquardt algorithm for global solar radiation estimation in Easter Mediterranean Region of Turkey. Journal of Cleaner Production, 10: 1-12. DOI : 10.1016/j.jclepro.2015.12.082

César, L.-V.E., C.-M. A. Lilia, G.-V. Octavio, P.F. Isaac and B.O. Rogelio, 2020. Thermal performance of a passive, mixed-type solar dryer for tomato slices (Solanum lycopersicum). Renewable Energy, 147(1): 845-855.DOI: 10.1016/j.renene.2019.09.018

Dadda, B., S. Kherrour and L. Serir, 2008. Réalisation d'un séchoir solaire indirect. Revue des Énergies Renouvelables SMSTS', 08: $127-134$.

Del Villa, P.M., T. Tran, A. Adayé, V. Bancal and K. Allanga, 2017. Analyse de la chaîne de manioc en Côte d'Ivoire. Rapport de l'Union Européenne, DG-DEVCO, Eds CIRAD Université Félix Houphouët-Boigny, Côte d'Ivoire.

Diallo, Y., M.T. Gueye, M. Sakho, P.G. Darboux, A. Kane, J-P. Barthelemy and G. Lognay, 2013. Importance nutritionnelle du manioc et perspectives pour l'alimentation de base au Sénégal (synthèse bibliographique). Biotechnologie, Agronomie, Société et Environnement, 17(4): 634-643.

Díaz, A., C. Dini, S.Z. Viña and M.A. García, 2018. Technological properties of sour cassava starches: Effect of fermentation and drying processes. LWT, 93: 116-123. DOI: 10.1016/j.lwt.2018.03.029

Djebli, A, S. Hanini, O. Badaoui, B. Haddad and A. Benhamou, 2020. Modeling and comparative analysis of solar drying behavior of potatoes. Renewable Energy, 145: 1494-1506. DOI: 10.1016/j.renene.2019.07.083

Elsheikh, A. H., S.W. Sharshir, M.A. Elaziz, A.E. Kabeel, W. Guilan and Z. Haiou, 2019. Modeling of solar energy systems using artificial neural network: A comprehensive review. Solar Energy, 180: 622-639. DOI: 10.1016/j.solener.2019.01.037

Faostat, 2017. http://www.fao.org/faostat/en/\#data/QC/visualize. On 10th April 2019

Jain, D., and G.N. Tiwari, 2003. Thermal Aspects of Open Sun Drying of Various Crops. Energy, 28(1): 37-54. DOI: $10.1016 / \mathrm{S} 0360-5442(02) 00084-1$

Kabran; E.E.A- M, M.K. Yao and A. Trokourey, 2019. Study of the traditional solar drying of six cassava varieties grown in Côte d'Ivoire. International Research Journal of Environmental Sciences, 8(4): under press.

Karidioula, D., D.C. Akmel, N.E. Assidjo and A. Trokourey, 2018. Modélisation du séchage solaire de fèves de cacao par le Réseau de Neurones Artificiel. International Journal of Biological and Chemestry Sciences, 12(1):195-202. DOI: $10.4314 /$ ijbsc.v12i1.15

Kaveh, M., V.R. Sharabiani, R.A. Chayjan, E. Taghinezhad, Y. Abbaspour-Gilandeh and I. Golpour, 2018. ANFIS and ANNs model for prediction of moisture diffusivity and specific energy consumption potato, garlic and cantaloupe drying under convective hot air dryer. Information Processing in Agriculture, 5(3): 372-387. DOI: 10.1016/j.inpa.2018.05.003

Levenberg, K., 1944. «A Method for the Solution of Certain Problems in Least Squares. » Quarterly of Applied Mathematics, 2: 164-168. DOI: $10.1090 /$ qam/10666

Lewis, W.K., 1921. The rate of drying of solid materials. Journal of Industrial and Engineering chemistry, 13:427-432.

Marquardt, D., 1963. An Algorithm for Least-Squares Estimation of Nonlinear Parameters. Journal of the Society for Industrial and Applied Mathematics, 11(2): 431-441. DOI: $10.1137 / 0111030$

Matlab Release 2019a, 2019. Matlab and simulink. The Mathwork Inc., Massachusetts, United State of America.

Mehran, S., M. Nikian, M. Ghazi, H. Zareiforoush and I. Bagheri, 2019. Experimental investigation and energy analysis of a solar-assisted fluidized-bed dryer including solar water heater and solar-powered infrared lamp for paddy grains drying. Solar Energy, 190: 167-184. DOI: 10.1016/j.solener.2019.08.002

Noumi, M., 2004. Painlevé equations through symetry. Translations of Mathematical Monographs, Vol. 223, Eds American Mathematical Society (AMS), United State of America.

Onwude, D.I., N. Hashim, K. Abdan, R. Janius and G. Chen, 2019. The effectiveness of combined infrared and hot air drying strategies for sweet potato. Journal of Food Engineering, 241: 75-87. DOI: 10.1016/j.jfoodeng.2018.08.008

Ouaabou, R., B. Nabil, N. Hidar, L. Lahnine, A. Idlimam, A. Lamharrar, H. Hanine and M. Mahrouz, 2018. Valorization of solar drying process in the production of dried Moroccan sweet cherries. Solar Energy, $172(2): 158-164 . \quad$ DOI: 10.1016/j.solener.2018.05.079

Rivadeneyra-Domínguez, E., A. Vázquez-Luna, J.F. Rodríguez-Landa and R. Díaz-Sobac, 2013. Neurotoxic effect of linamarin in rats associated with cassava (Manihot esculenta Crantz) consumption. Food and Chemical Toxicology, 59:230-235. DOI: $10.1016 /$ j.fct.2013.06.004 
Seerangurayar, T., A.M. Al-Ismaili, L.H.J. Jeewantha and N.A. Al-Habs, 2019. Effect of solar drying methods on color kinetics and texture of dates. Food and Bioproducts Processing, 116: 227-239. DOI: 10.1016/j.fbp.2019.03.012

Sherwood, T.K., 1929. The drying of solids. Industrial and Engineering Chemistry, 21(10): 12-16. DOI: 10.1021/ie50229a004

SODEXAM, 2016. Rayonnement global mensuelle à Abidjan de 1988 à 2016. Eds SODEXAM, Abidjan, Côte d'Ivoire.

Tieu, Z.A., P. Gbaha and K.A. Diby, 2019. Étude expérimentale d'un grenier séchoir solaire à convection naturelle: Application au séchage du cacao et du manioc. Afrique Sciences, 15(2): 80-95.

Torkashvand, A.M., A. Ahmadi and N.L. Nikravesh, 2017. Prediction of kiwifruit firmness using fruit mineral nutrient concentration by artificial neural network (ANN) and multiple linear regressions (MLR). Journal of Integrative Agriculture, 16(7): 1634-1644. DOI: $10.1016 / \mathrm{S} 2095-3119(16) 61546-0$

Wang, P., D. Mohammed, P. Zhou, Z. Lou, P. Qian and Q. Zhou, 2019. Roof solar drying processes for sewage sludge within sandwich-like chamber bed. Renewable Energy, 136: 1071-1081. DOI: 10.1016/j.renene.2018.09.081

Wilkins, R., J. Brusey and E. Gaura, 2018. Modelling uncontrolled solar drying of mango waste. Journal of Food Engineering, 237: 44-51. DOI: 10.1016/j.jfoodeng.2018.05.012

Yahya, M., A. Fudholi, H. Hafizh and K. Sopian, 2016. Comparison of solar dryer and solar-assisted heat pump dryer for cassava. Solar Energy, 136: 606-613. DOI: 10.1016/j.solener.2016.07.049

Yao, M.K, K.L. Akpetou, Y.S. Brou, D.C. Akmel, A. Trokourey, K.B. Yao and N.E. Assidjo, 2016a. Eutrophication modeling by new approach in tropical lagoon bay: Case of Tiagba. Australian Journal of Basic \& Applied Sciences 10(13): 37-44.

Yao, M.K., L. Agbri, B.S. Bamba, M.B. Soro and A. Trokourey, 2016b. Prédiction de l'évolution spatio-temporelle du fer à l'exutoire d'un fleuve tropical : cas du fleuve Sassandra à Gaoulou (Côte d'Ivoire). International Journal of Biological and Chemical Sciences, 10(6): 2768-2780. DOI: 10.4314/ijbcs.v10i6.29

Yao, M.K., D.C. Akmel, K.L. Akpetou, A. Trokourey, K.B. Yao and N.E. Assidjo, 2017. Modélisation de l'évolution spatiotemporelle du phosphore minéral dans une baie lagunaire hypereutrophe tropicale : la baie lagunaire de Tiagba (Côte d'Ivoire). Revue de Sciences de l'Eau, 30(3): 247-258. DOI: 10.7202/1044250ar 